\title{
Understanding The Impact Of Gender By Imagining The Self As The Other Gender: A Role-Play Writing Assignment
}

\author{
Katherine A. Black, (Email: kablack@hartford.edu), University of Hartford
}

\begin{abstract}
To encourage students to think about and understand the considerable role gender plays in their lives, a writing assignment early in a gender course asks them to consider the impact of permanently becoming the other gender. Students' papers were examined for particular themes, which were used to illustrate course concepts and to spark class discussions. For example, some students wrote that they must learn how to be the other gender, which leads to a discussion about the sources of gender differences. Other themes as well as suggestions for expanding the assignment are discussed.
\end{abstract}

\section{INTRODUCTION}

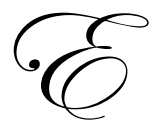

arly in the semester, students in gender courses often claim that gender has only a minor, if any, impact on their feelings and behavior. Some cite the Women's Movement as a historical period when gender mattered, and state "We're beyond all that now." Such statements suggest some students believe gender influences individuals during times when gender roles are changing dramatically, but at other times, the influence of gender is negligible. Numerous research studies have, of course, revealed that gender has a considerable impact on how we feel and behave as well on how others perceive and treat us. One possible reason for this gap in students' understanding is that they are too embedded in their own gender to see its effects. If this is the case, then an assignment that asks them to step out of their gender, by imagining themselves as the other gender, may not only serve to illustrate course concepts but also to convince them of the significant role that gender plays in their lives.

College instructors have used role-playing exercises to enhance students' understanding of course concepts. For example, students in a course on adult development and aging were randomly assigned to small groups, or "classroom families" (Jarrott \& Blieszner, 2001). Although students could develop any persona they wished to fulfill within the family, two members had to be more than 65 years old, two had to be between 35 and 65 , and the remaining members could be any age. In family meetings scheduled throughout the semester, classroom families were asked to role play and respond to various scenarios, such as effectively caring for a terminally ill family member and preparing for a family member's retirement. In a survey at the end of the semester, students commented that the family meetings enhanced their learning by allowing them to apply the course material to realistic situations.

Role-playing assignments also enhance students' appreciation of others' experiences. The instructor of a cross-cultural psychology course divided the students into two groups and asked each group to assume its own distinct culture (Tomcho, 2002). Some of the features of the culture, like the currency, entertainment activities, and foods, were defined by the instructor. To promote identification with the culture, students in the group decided about some other features of their culture, such as its name. In a series of "cultural exchanges" around defined topics, members of one group visited the other group. For example, in one exchange, the visitors were hungry but could not find food native to their own country and they were unfamiliar with the exchange rate for the currency they carried. In another scenario, one of the visitors needed medical attention, but the visitors could only use nonverbal communication to get help. After the cultural exchanges, the visitors reported on their experiences. Students 
reported how frustrating it was that they could not find what they were looking for or communicate in the other culture. On a survey, students strongly agreed that the cultural exchanges increased their empathy for those who move to or come in contact with a different culture.

Finally, in enhancing students' understanding of others' experiences, role-playing exercises can increase students' understanding of themselves. For example, students in a course on abnormal psychology were asked to write a biography of a character with a psychological disorder and then to role play that character in one of three staged settings: a psychiatric ward, a special-education classroom, or a party (Poorman, 2002). While some students were acting out their characters, the rest of the class interacted with and diagnosed the characters. Based on pre- and post-assignment scores on an empathy measure, it was clear that students' empathy for those suffering from mental illness increased. In addition, in follow-up interviews, students reported that the role-playing exercise reduced their stereotypes of individuals with psychological disorders and helped them understand the difficulties mentally ill individuals experience everyday. Students also reported learning a lot about themselves. Indeed, one student said, "maybe all of us have a little part of all of these disorders in ourselves" (Poorman, 2002, p. 34).

Taken together, these exercises involve students taking on the role of characters different from themselves to better understand course concepts, to better appreciate others' experiences, and in many cases, to better understand themselves. In a similar vein, I used a writing assignment, which asks students to consider the implications of permanently becoming the other gender. In this way, their beliefs about gender may become more apparent. And discussing these beliefs may serve to illustrate course concepts and to encourage students to think about the significant role gender plays in others' lives as well as their own.

\section{THE COURSE AND THE STUDENTS}

At the University of Hartford, there is a nationally recognized inter-disciplinary undergraduate curriculum, referred to as the All-University Curriculum (AUC) (Seabury, 1999). The roughly 30 AUC courses offered are divided into five major areas: science and technology, social context, arts, Western heritage, and other cultures. All undergraduate students are required to take a course in four out of the five areas. The key strength of these courses, which are often team taught, is the examination of a particular topic (e.g., hunger, ethics, the environment) from multiple perspectives.

One of the courses in the social context area, entitled "Gender, Identity, and Society," focuses on the role of gender in our lives as investigated by multiple disciplines. I taught this course for the first time a few semesters ago. I am a developmental psychologist by training. One of my areas of research is the study of gender differences in social interaction behavior and judgments of others. Although I have taught a "Psychology of Gender" course several times within my own department, I had never taught an inter-disciplinary course on gender. I chose Michael Kimmel's (2004) The Gendered Society text, which approaches the study of gender through anthropological, biological, psychological, and sociological lenses. I supplemented this text with readings from Sandra Bem (1998), Dan Kindlon and Michael Thompson (2000), Mary Pipher (1994), and Deborah Tannen (1990), among others. I utilized a discussion-based format. Students were expected to read the assigned material before class and to be prepared to actively participate in discussions of that material. In addition, they were asked to write several short reaction papers to the readings and several longer papers on topics I provided. I will focus on one of these longer writing assignments here.

In addition to examining a topic from multiple perspectives, another strength of the AUC curriculum is bringing students from various disciplines together to learn and inform each other about the topic of study. There were 28 students (19 women, 9 men) in the gender course, representing various colleges on campus. There were students in liberal arts, business, engineering, music theatre, dance, and music. It was clear, from our discussions, that students differed dramatically in their attitudes about gender as well as in their tolerance for others' beliefs. 


\section{THE ASSIGNMENT}

The assignment was originally introduced to me by Professor Louise Rosenberg at the University of Hartford during an AUC workshop for the gender course, and I made minor modifications to it before giving it to my class.

The assignment reads as follows: "Imagine that you wake up one morning to find that you have become the other sex - if you were male, you are now female, and if you were female, you are now male. There is no explanation for this startling change. As the day progresses, it becomes clear that this change is permanent. In a five-page paper, describe the implications this switch will have on your life. Discuss as many aspects of your life as you can (including those areas where you think there would be no implications). Here are some examples of areas you could include in your discussion: physical characteristics; activities; goals; relationships with family, friends, and romantic partners; school and work experiences."

As I read through their papers, it was clear that the students had taken the assignment quite seriously and were very thoughtful in their responses. I also noticed that particular themes began to emerge. These themes were used to illustrate course concepts and to spark class discussions. The five examples of themes cited below are exemplified by anonymous quotes from students' papers (with their permission). As each quote is from a different student, half of the students in the class are quoted here.

\section{THE FIVE THEMES}

The first theme dealt with the physical transformation that the students imagined they would undergo. Most wrote that they would be quite unnerved by the physical changes. And in fact, some were so unnerved that they wrote in great detail and spent the majority of their paper discussing the various physical implications of changing genders. One woman wrote, of becoming a man, "My once delicate, tiny, shaven legs were now thick hairy trunks...My feet were huge! There were hairs on my toes and the toenails I had polished last night were now yellow and overgrown...My entire body, once petite and slender had transformed into this monster...this tall, muscular, hairy mess of a body with broad shoulders and thick legs." One man wrote, of becoming a woman, "I no longer had the deep voice like I had the night before. Instead my voice was light and soft...My braids had grown down to my shoulder; [my hair] felt softer than it normally did. I noticed that my face was slimmer and my facial features had changed. My nose and lips were smaller and my eyelashes were a little longer. I did not have an Adam's apple anymore. I stared at my chest and to my surprise I had developed breasts. My stomach no longer had the muscles that I had worked to develop but instead it was small like I haven't eaten anything in a few days. My legs were slim and smooth...My skin was silky and soft to the touch. I looked at my hands and they were smaller and slimmer. My fingernails had grown overnight and the texture of my hands was different from before...I looked at my hips and they had become wider and shapely." This theme leads to a discussion about the physical differences between men and women. Research findings suggest that the largest and most consistent differences between men and women are physical, rather than cognitive or social-emotional. In addition, many of these differences are readily apparent, simply by looking at men and women. Perhaps this explains why some students focused on the physical changes they would experience, as these represent the most obvious gender differences. The woman quoted above focused on her larger physical stature as a man and the increase in body hair. The man quoted focused on his smaller stature and the "softness" of his features.

Although some students focused on the physical transformation they would undergo if they changed genders, most students also wrote about changes in their feelings and behavior. The second theme illustrates that the changes they anticipated were often stereotypical in nature. For example, here are a few quotes from women about becoming men:

Now that I am a guy I would be expected to play football and do things that involve more physical contact, like wrestling...I would watch dangerous shows involving killing and any other dangerous activity...I would do other activities such as fix cars that include knowing all the different car parts. 
I would probably have to learn to play video games and probably would have to practice different sports to promote male bonding.

I probably should not let my emotions affect me publicly.

And here are several quotes from men about becoming women:

I would probably be thinking about a wedding of some sort and the perfect match for me out there.

I went to bed last night a man, and woke up as a cranky, demanding, emotional, self-conscious, bleeding pile of flesh.

These quotes lead to a discussion about stereotypes, which is informed by two psychological theories. The first is social learning theory, which suggests that we learn behaviors and attitudes by observing and imitating others (Bandura, 1977). By the age of two, we learn that we are either girls or boys. Once we can categorize ourselves and others, we spend a lot of time observing and then imitating others in our own category, presumably so that we learn how to fit in. Although we observe members of the other category, we spend comparably less time on such observations. The second theory that informs this discussion is gender schema theory, which suggests that we construct gender schemas, or categories, to organize the information we know that is relevant to gender (Martin \& Halverson, 1981). As we learn, new information is tagged for the categories labeled "male" or "female." Because we have spent enormous amounts of time observing individuals in our same gender category, we have detailed information about their characteristics, abilities, and behavior. We have less detailed information about the characteristics, abilities, and behavior of the other gender. The consequences of the differential sizes of our cognitive networks for males and females is that we understand the great variability among members of our own gender group, but we stereotype members of the other gender group as "all the same" (e.g., Frable \& Bem, 1985). As demonstrated by the quotes above, stereotypical thinking about the other gender was glaringly apparent in the students' papers. Women who wrote about becoming men assumed that they would now enjoy playing sports and video games and fixing cars, and would avoid displaying emotions in public. Men who wrote about becoming women, on the other hand, assumed they would be highly emotional and self-conscious and would be obsessed with finding and marrying a partner.

The third theme dealt with the sources of gender differences. Students are often quick to assume that gender differences are innate, and are less willing to recognize the role of socialization. Yet, in describing their new lives, some students wrote that they must learn how to be the other gender, and to do so, they must observe other members of that gender. One woman wrote about becoming a man, "It would be in my best interest to hang out with my dad a little more than before. By doing that I could pick up on some male traits and how males react to certain situations." Another woman wrote, "I can no longer sit the way I used to. People will start to look at me weird. So I look at a guy near me and follow his sitting behavior. I have to open my legs a little more and scrunch a little. I am starting to think that if I just look at the guys around me, I might be able to pull this off." One man wrote about becoming a woman, "I would probably be forced to actually 'study' other females to truly get a sense of how I was expected to act in any given situation. This observation would be essential to learning how to dress, walk, eat or any other activity that might be different for a woman than for a man." If students believed that they must learn how to be the other gender, perhaps they are willing recognize that they had to learn how to be the gender they are. This leads to a discussion about the socialization of gender roles. Students who grew up with other-gender siblings are often the first to recognize the differential treatment of the two genders, as their parents assigned different chores to the boys and the girls or bought them different toys. This discussion is then expanded to include other sources of socialization, such as peers, teachers, and the media. In keeping with social learning theory, the students quoted above recognized they would observe same-gender parents and peers to determine the traits and behavior expected of their new gender.

Understanding that society treats boys and girls, and men and women, differently is a precursor to understanding that society has differential expectations of the two genders. And differential expectations might influence, boys' and girls' as well as men's and women's aspirations for themselves, which was the subject of the 
fourth theme. As an example, some students wrote that their career goals would change as a result of changing genders. One woman wrote, of becoming a man, "I really have never thought about my future as much as I am now. I feel like now that I am a man I have more responsibilities such as bills and getting a decent job to support my family...and I feel like as a man I have to be more dependable and be the one to make all the money, unlike before when I was a woman all I thought about was mainly staying home to take care of the kids while my husband worked." One man wrote, of becoming a woman, "I would seriously consider not entering into any large corporate companies...Instead I would be more likely to work for a smaller company where my contributions could be better seen or start my own company in which I have much greater control over my success and future." Such quotes lead to a discussion about how our perceptions of society's expectations of men and women might influence the choices we make in such important decisions as our careers. Indeed, the woman's words quoted above suggest that she expects men to be responsible for the financial well-being of their families and expects women to care for children. As such, as a man, she would think a lot more about her career than she did as a woman when she thought she was going to stay home to take care of children. And, in delineating these differential roles, she suggests that a man must be more dependable than a woman. The man quoted above is concerned about the probability of being successful as a woman in a large company. He suggests that this concern would impact his career choices, in that he would choose to work in a smaller company or start his own business.

As would be expected, and as is clear from the quotes already included, most of the students focused on the changes they would undergo, whether those were physical, behavioral, or emotional. The fifth theme illustrates that gender may not impact every aspect of who we are. A few students wrote that a core part of who they are would not change even if their gender changed. One woman wrote, of becoming a man, "I always like to be and do the best at whatever I'm doing... That would be one thing about me that wouldn't change if I were to become a man." One man wrote, of becoming a woman, "I also will be the same kind of person I am now, and I won't let some freak event like changing into a woman affect that." Such quotes lead to a discussion about the role of gender in our sense of self. Although most individuals include their gender when asked to describe themselves, the students' quotes suggest that there are aspects of the self that can be separated from gender. The woman's quote suggests that she would value striving for excellence in everything she does regardless of her gender. The man's quote suggests that his personality would not change even if his gender changed.

There is a caveat here. The influence of gender on our sense of self may also be indirect. Our sense of self is often defined by how others view us and communicate that view to us. A child whose teachers and parents believe he or she is good in math, for example, tell the child this on a regular basis. Before long, the child comes to view him/herself as good in math. However, others' beliefs about us are influenced by our gender. Teachers and parents may be more likely to communicate to boys that they are good in math if they believe that boys, more so than girls, are naturally gifted in math. If boys are more likely to hear from others about their good math skills, boys may be more likely to incorporate such skills into their sense of self. In other words, although there may be definitions of ourselves that are not tied to gender, we should be cautious in drawing that conclusion.

\section{CONCLUSIONS AND FUTURE DIRECTIONS}

Several themes emerged based on students' responses to this assignment, and these themes provided the foundation for very fruitful class discussions about course concepts. By students imagining themselves as the other gender, their beliefs about gender became very apparent. Indeed, I would argue that this assignment gave me more insight into their beliefs than if I had asked them their beliefs outright. As such, the themes provided a more honest starting point for class discussions. In discussing the themes that emerged from the students' papers, the significant role gender plays in how they look, how they feel and behave, and the choices they make became more clear.

Although I chose to present five of the themes, the papers provided countless other themes that could be extracted and used to illustrate course concepts. As an example, several students described how their parents would react to the change in their gender. Men, in particular, were concerned about their father's reaction, stating that their father would be "upset," "furious," or that society would pass judgment on him and "hold him partly responsible no matter what." These anticipated reactions support previous research that fathers are more concerned about their children's gender role behavior, particularly their son's, than are mothers. 
Students informally commented to me about how much they enjoyed this assignment and how they had never before thought about how important gender is in their lives. In my judgment, using students' own responses to illustrate key concepts uniquely captured their attention in class and increased significantly their level of engagement in the discussion. In the future, it would be helpful to collect more systematic and anonymous quantitative and qualitative data on students' perceptions of the assignment's usefulness to their understanding of gender issues.

The assignment could also be expanded in a number of ways to encourage students to draw connections between their lives and the course concepts. The paper could be assigned in the first week of the semester. Then, toward the end of the semester, the students could be asked to review and analyze their own writing, using their own examples to illustrate the concepts they learned in class. This kind of self-reflection about their gender beliefs is an important skill to foster and will serve them well long after their college experience.

In keeping with the previous work on the use of role playing in the classroom, an alternative assignment would be to ask students to take on roles as the other gender. As a small number of students act out their characters, the class could analyze the role plays using the concepts they learned throughout the course. In the Poorman (2002) study, the students reported that their increased empathy for those with mental illness was due, in part, to the realism of the role-playing exercise. Thus, a role-playing exercise for the two genders would need to be as realistic as possible. The idea is to encourage students to step out of their own gender and imagine what their lives would be like as the other gender. Such assignments not only serve to illustrate course concepts, but they also elucidate the significant impact that gender has on all of our lives.

\section{REFERENCES}

1. $\quad$ Bandura, A. (1977). Social learning theory. Englewood Cliffs, NJ: Prentice-Hall.

2. Bem, S. L. (1998). An unconventional family. New Haven, CT: Yale University Press.

3. Frable, D. E. S., \& Bem, S. L. (1985). If you are gender schematic, all members of the opposite sex look alike. Journal of Personality and Social Psychology, 49, 459-468.

4. Jarrott, S. E., \& Blieszner, R. (2001). Creating families in the classroom: An active learning approach. Gerontology and Geriatrics Education, 22, 15-27.

5. Kimmel, M. S. (2004). The gendered society. New York: Oxford University Press.

6. Kindlon, D., \& Thompson, M. (2000). Raising Cain: Protecting the emotional life of boys. New York: Ballantine Books.

7. Martin, C., \& Halverson, C. (1981). A schematic processing model of sex typing and stereotyping in children. Child Development, 52, 1119-1134.

8. Pipher, M. (1994). Reviving Ophelia: Saving the selves of adolescent girls. New York: Ballantine Books.

9. Poorman, P. (2002). Biography and role playing: Fostering empathy in abnormal psychology. Teaching of Psychology, 29, 32-36.

10. Seabury, M. B. (Ed.) (1999). Interdisciplinary general education: Questioning outside the lines. New York: College Entrance Examination Board.

11. Tannen, D. (1990). You just don't understand: Women and men in conversation. New York: Harper Collins.

12. Tomcho, T. J. (2002). Teaching acculturation: Developing multiple 'cultures' in the classroom and roleplaying the acculturation process. Teaching of Psychology, 29, 226-229. 